Onomástica Desde América Latina, n.4, v.2, julho - dezembro, 2021, p. 70-94. ISSN 2675-2719 https://doi.org/10.48075/odal.v0i0.27562

\title{
Proposta de definição interdisciplinar de nome próprio
}

\section{Proposal of interdisciplinary definition of proper name}

\author{
Márcia Sipavicius Seide \\ Universidade Estadual do Oeste do Paraná \\ https://orcid.org/0000-0003-2859-1749 \\ Marcia.Seide@unioeste.br
}

\begin{abstract}
Resumo: Este artigo apresenta uma proposta de definição interdisciplinar do conceito de nome próprio elaborada com base na Onomástica Cognitiva (SJÖBLOM, 2010), na Teoria da Relevância (SPERBER \& WILSON ,2001 [1995], SEIDE \& SCHULTZ, 2014), na Neurolinguística (VAN LANGENDONCK, 2007), e no conhecimento onomástico do falante ideal (SEIDE, 2021). Na primeira seção deste artigo, descrevem-se o objeto de estudo da Onomástica e as características da subárea da Onomástica em que se insere a pesquisa. Na segunda, são retomadas considerações a respeito dos nomes próprios feitas para sua definição como endereço conceitual. Na terceira seção, apresentam-se as descobertas neurolinguísticas e a descrição do conhecimento onomástico do falante ideal, as quais são integradas resultando na redefinição de nome próprio descrita ao final da terceira seção. Na quarta e última seção do artigo, são descritas algumas implicações dessa redefinição para os estudos onomásticos.
\end{abstract}

Palavras-chave: Nome próprio, Onomástica Cognitiva, Teoria da Relevância, Neurolinguística, Conhecimento Onomástico do Falante Ideal.

\begin{abstract}
This article makes a proposal of interdisciplinary definition of the concept of proper name based on Cognitive Onomastics (SJÖBLOM, 2010), Theory of Relevance (SPERBER \&WILSON, 2001 [1995], SEIDE \& SCHULTZ, 2014, Neurolinguistics (VAN LANGENDONCK, 2007) and the onomastic knowledge of the ideal speaker (SEIDE, 2021). In the first section of this article, the object of study of Onomastics and the characteristics of the onomastic subarea in which the research is included are described. In the second, considerations about proper made by Sperber and Wilson (2001 [1995]) are integrated to the definition of proper names as a conceptual address. In the third section, the neurolinguistic discoveries and the description of the onomastic knowledge of the ideal speaker are presented and integrated and the proper name redefinition is described. In the fourth and final section of the article, some implications of this redefinition for onomastics studies are described.
\end{abstract}

Keywords: Proper name, Cognitive Onomastics, Relevance Theory, Neurolinguistics. Onomastic Knowledge of Ideal Speaker.

\section{Introdução}

Em junho de 2021, foi publicado um número temático sobre Onomástica na revista Domínios da Lingu@gem. Na apresentação do número, os editores comentam que tinham o desiderato de reunir pesquisas interdisciplinares na área, mas não conseguiram transformar seu desejo em realidade, tendo em vista que apenas alguns artigos entre os recebidos e aprovados para publicação eram realmente interdisciplinares. A escassez de trabalhos desta natureza é explicada por eles da seguinte maneira: 
Efetivamente, a interdisciplinaridade é um desafio perseguido, mas nem sempre alcançado. Como postularemos adiante, isso ocorre por vários motivos. Seja pela incompreensão real do que é a interdisciplinaridade - pela ambiguidade entre este conceito e concepções correlatas como pluri ou transdisciplinaridade -, seja por entraves relacionados à situação atual da pesquisa no Brasil, a interdisciplinaridade é muito mais uma demanda que uma factualidade. (CARVALINHOS e SANTOS, 2020 p.265)

Não obstante o acerto e precisão do diagnóstico do estado de arte dos estudos onomástico do Brasil realizado por Carvalinhos e Santos, a causa para a ausência de estudos interdisciplinares pode estar relacionada à inexistência de uma definição também interdisciplinar do objeto de estudo desta área do conhecimento: o nome próprio. Partindo-se deste pressuposto, este artigo apresenta uma redefinição interdisciplinar dos nomes próprios que pode respaldar estudos nos quais se procura a religação os saberes linguísticos, culturais, sociais e históricos acerca do que são, como são usados e os motivos pelos quais são os nomes próprios escolhidos e utilizados. Outra contribuição da redefinição ora proposta, como se explicita na última seção do artigo, é sua aplicação epistemológica uma vez que quando se parte de uma noção mais complexa e abrangente de nome próprio é possível identificar exatamente o que a respeito do nome próprio é foco de atenção de pesquisador de Onomástica em suas pesquisas.

Ainda nesta introdução, é preciso expressar publicamente minha gratidão aos parecerista do meu artigo cuja leitura atenta e cuidadosa foi fundamental para o aperfeiçoamento do texto. Falhas e incorreções que por ventura existirem são de minha responsabilidade. Também necessito externar a contribuição direta ou indireta de todos meus orientandos e alunos de Onomástica cuja curiosidade e cujos problemas de pesquisa me inspiram a avançar nesta seara. 
Onomástica Desde América Latina, n.4, v.2, julho - dezembro, 2021, p. 70-94. ISSN 2675-2719 https://doi.org/10.48075/odal.v0i0.27562

\section{A Onomástica e a Onomástica Cognitiva}

A Onomástica é uma área de estudo que se caracteriza por seu objeto de estudo: os nomes próprios. Apesar de o interesse pelos nomes próprios ser antigo, a criação de uma área a eles destinada é mais recente e acompanhou o desenvolvimento dos estudos filológicos e o advento da Linguística Comparada no começo do século XIX (AMARAL\& SEIDE 2020: 35). Ao longo do século XX, a área foi ganhando força em várias partes do mundo, com inclusão do Brasil. No Brasil, enquanto as pesquisas sobre os nomes próprios de lugares (os topônimos) foram alavancadas pelas iniciativas da profa. dra. Maria Vicentina de Paula Amaral Dick da Universidade de São Paulo, os primeiros estudos concernentes aos nomes próprios de pessoas (os antropônimos) foram desenvolvidos pelo prof. dr Farânio Mansur Guérios da Universidade Federal do Paraná (SEIDE \& SAPARAS 2020). Atualmente, a área se caracteriza por sua amplitude e diversidade uma vez que congrega pesquisadores de várias áreas do conhecimento e diferentes metodologias e fundamentações teóricas.

Perante esta heterogeneidade constitutiva, o nome próprio funcionaria como denominador comum dos estudos onomásticos. A este respeito, chama a atenção o fato de o conceito de nome próprio não ter se alterado ao longo do último século e começo deste em gramáticas normativas e descritivas da Língua Portuguesa. Seis gramáticas prescritivas publicadas ao longo do século XX (ALMEIDA, 1961, CEGALA, 1964, CUNHA\& CINTRA, 1985, 2008, FARACO, 1990; PEREIRA JUNIOR 1924 e REUNIÃO DE PROFESSORES, 1937) e três gramáticas descritivas publicadas nas primeiras décadas deste século foram consultadas. (BECHARA, 2015, CASTILHO 2010, NEVES, 2000). Em todas elas, houve a utilização de uma mesma definição de nome próprio, a saber: a de nome próprio como um item lexical caracterizado por sua univocidade, isto é, pelo fato de este nome ser utilizado para fazer referência a um ser 
Onomástica Desde América Latina, n.4, v.2, julho - dezembro, 2021, p. 70-94. ISSN 2675-2719 https://doi.org/10.48075/odal.v0i0.27562

visto ou caracterizado como único (SEIDE, no prelo). Este achado confirma o apontado por Amaral e Seide (2020: 57) e vai ao encontro da definição por eles postulada para o nome próprio:

Possibilitam a identificação direta de um referente único em um universo de conhecimento compartilhado por emissor e receptor. Possuem capacidade de referir, independentemente da presença de determinante.

Não apresentam traços semânticos identificadores de classe. São grafados com maiúscula inicial (AMARAL \& SEIDE: 58)

Ainda segundo Amaral e Seide, a definição de nome próprio e a distinção entre nome próprio e nome comum sempre estiveram presentes nas gramáticas desde os gregos até hoje e que nas gramáticas da língua portuguesa (descritivas ou normativas), as definições e os exemplos são convergentes. Este consenso acerca do que caracteriza o nome próprio quanto ao ao seu uso mais prototípico inexiste no que diz respeito às suas características semânticas. Há as teorias que postulam não haver significado algum nos nomes próprios a exemplo de Mill (1984) e aquelas que defendem a tese antípoda: a de que os nomes próprios são mais significativos que os nomes comuns como defende Bréal (1992 [1904]). Atrelada a esta questão, há outra: a da distinção entre o universal e o particular.

Se há um consenso entre gramáticos e onomasticistas com relação à natureza particular dos nomes próprios, o que implica serem os nomes comuns de natureza universal, o mesmo não ocorre com os filósofos. A discussão filosófica a respeito destes conceitos auxilia na compreensão de como os nomes próprios são usados e do motivo pelo qual eles são necessários e imprescindíveis a todas as línguas, inclusive àquelas que não foram criadas espontaneamente, como é o caso do Esperanto, por exemplo.

Uma das questões postuladas pelos filósofos foi justamente sobre a possibilidade de se conceber uma língua ideal, na qual não haveria nenhum termo singular definido. Segundo Tunhas (2001), na década de 1960, Quine havia proposto que isto seria 
Onomástica Desde América Latina, n.4, v.2, julho - dezembro, 2021, p. 70-94. ISSN 2675-2719 https://doi.org/10.48075/odal.v0i0.27562

possível mediante sua substituição por paráfrases. A esta proposta se opôs Strawson cuja contra argumentação é assim descrita pelo filósofo português:

\begin{abstract}
Strawson mostra (...) que Quine oscila entre duas teses uma tese forte e uma tese fraca: a tese forte afirma que os termos são supérfluos, isto é, inexistentes, a tese fraca afirma que eles podem ser dispensados por paráfrase. Apenas a tese forte concebe a efetiva possibilidade de uma linguagem sem termos singulares, a tese fraca limita-se a propor uma linguagem em que os termos singulares existem, mas onde podem ser sistematicamente parafraseados de forma a serem artificialmente substituídos por frases que não os contém. E certamente a tese forte não é derivável da tese fraca a compreensão da paráfrase exige a suposição dos próprios termos singulares que são parafraseados (TUNHAS, 2001:336).
\end{abstract}

Interessa aos propósitos deste artigo a ideia de que um nome próprio pode ser substituído por uma paráfrase, a qual pode ser expressa linguisticamente por frases, tendo em vista que foi a partir desta possibilidade que Strawson concluiu que o significado dos nomes próprios equivale ao conjunto de descrições definidas que a ele pode ser associado ou atribuído (AMARAL \& SEIDE, 2020: 143). Sobre esse pressuposto da chamada Teoria Descritivista dos nomes próprios, Costa (2009:186) esclarece que "as flutuações no sentido não podem ser tão grandes a ponto de impedir a comunicação. Se duas pessoas associam descrições totalmente diferentes de um nome próprio, perde-se a unidade do sentido".

Ainda de acordo com o mesmo filósofo, as referidas flutuações de sentido decorrem do fato de cada pessoa atribuir ao referente de um determinado nome próprio, diferentes conjuntos de descrições definidas, sendo então necessário que haja pelo menos uma descrição em comum aos interlocutores para que seja garantida a compreensão compartilhada sobre de quem ou do que se está falando. Há que esclarecer, além disso, que, em função do contexto comunicativo, nem todas as descrições atribuídas ao referente serão ativadas, mas apenas aquelas que forem pertinentes, dadas as circunstâncias da interlocução. Importa ressaltar que esta univocidade pragmática, isto é, o fato de um nome próprio ser usado numa situação 
Onomástica Desde América Latina, n.4, v.2, julho - dezembro, 2021, p. 70-94. ISSN 2675-2719 https://doi.org/10.48075/odal.v0i0.27562

comunicativa para fazer referência a uma entidade singular, é atualmente explicada de um ponto de vista cognitivo:

[...] o sentido completo de um nome próprio é constituído por um conjunto de valores cognitivos (sentidos) geralmente exprimíveis através de descrições; cada falante tem geralmente acesso a um subconjunto desse conjunto de valores cognitivos; mas esse acesso precisa ter em comum ao menos o suficiente para que os falantes possam saber que estão falando da mesma coisa. É preciso que os dois conjuntos de descrições pelo menos se interseccionem (COSTA, 2010:187)

Esta vertente cognitiva, além de ter influenciado os estudos filosóficos, também

acarretou mudanças na Linguística com o surgimento da Linguística Cognitiva, assim

definida:

O estudo cognitivo da linguagem é (...) uma tendência a ver a linguagem como uma parte da cognição humana em geral. A abordagem cognitiva também leva em consideração a cultura e a interação: a linguagem não é vista somente como um fenômeno mental, mas também como um fenômeno cultural. Não há uma divisão clara entre língua, sistema e uso linguísticos, e a língua é um sistema dinâmico que está sempre mudando. O propósito deste método de pesquisa é propor explicações linguísticas que se apliquem ao significado e às motivações peculiares ao usuário da língua. ${ }^{1}$ (SJÖBLOM, 2010: 66-67) (trad.minha).

Inspirados na Linguística Cognitiva surgiram estudos onomásticos baseados nessa teoria, principalmente por iniciativa de pesquisadores finlandeses, dando origem a uma nova subárea dos estudos onomásticos, a Onomástica Cognitiva também parte do princípio de que os nomes próprios são significativos, mas considera que fazer referência a um ser concebido como singular, individual e singular não é a única função dos nomes próprios tendo em vista que:

O argumento por detrás da ideia de que os nomes não tem significado é o de que a única função de um nome próprio é a individualização. Recentemente, este argumento foi questionado. No que concerne os nomes não oficiais de cidades, por exemplo, descobriu-se que as pessoas usam nomes com outro propósito, não apenas para individualizar. Se um lugar já tem um nome próprio, a individualização não pode sequer ser a função primária do nome não oficial; nestes casos, o nome é usado para expressar imagens relativas ao

\footnotetext{
${ }^{1}$ The cognitive study of language is (...) a tendency to see language as a part of general human cognition. The cognitive approach takes into consideration culture and interaction as well: language is seen not only as a mental, but also as a cultural phenomenon. There is no sharp boundary between language system and language use, and language is a dynamic and always changing system. The purpose of the research method is to produce language related explanation that aplly to meaning and motives typical to the user.
} 
Onomástica Desde América Latina, n.4, v.2, julho - dezembro, 2021, p. 70-94. ISSN 2675-2719 https://doi.org/10.48075/odal.v0i0.27562

lugar (...) O mesmo fenômeno ocorre, por exemplo, com nomes de pessoas não oficiais. O pré requisito para ridicularizar alguém intencionalmente usando um nome abusivo é, acima de tudo, que o nome contenha determinado significado que possa ser interpretado de determinada maneira ${ }^{2}$ (SJÖBLOM, 2010:65). (trad.minha)

Como se pode perceber, a definição das funções a que se pode prestar os nomes próprios é mais ampla daquela defendida pelos gramáticos citados neste artigo e por Amaral e Seide (2020) pois abrangem conotações e usos que vão além da função pragmática dos nomes próprios prototípicos e apontam para a necessidade de se propor uma redefinição interdisciplinar de nome próprio. Além disso, os diferentes tipos de nomes próprios citados pela pesquisadora finlandesa exemplificam a diversidade desta classe de palavras cujo elenco, inclusive, varia de autor a autor e também pode ser mais ou menos abrangente de uma língua para outra (AMARAL\& SEIDE, 2020, p. 59 - 63). Do ponto de vista teórico, a proposta de redefinição de nome próprio se fundamenta na vertente cognitiva dos estudos onomásticos ora apresentada, na Teoria da Relevância, nos achados neuro-linguísticos e no conhecimento onomástico do falante ideal. A seção a seguir trata da primeira teoria mencionada.

\section{O nome próprio como endereço conceitual}

Não sendo possível tratar dos nomes próprios sem que se faça menção, mesmo que para efeito de contraste, aos nomes comuns e demais itens que compõem o léxico de uma língua natural, é preciso trazer para esta seção as afirmações dos criadores da Teoria da Relevância (SPERBER \& WILSON, 2001 [1995]) sobre o significado das palavras. Em primeiro lugar, Sperber e Wilson advertem que adotam um viés eclético

\footnotetext{
${ }^{2}$ The argument behind the idea that names have no meaning is that the only function of a proper noun is individualization. In recent times this argument has been questioned, with regards to unofficional city names, for example, it has been found that people use names for other purposes, than just individualizing. If a place already has a proper name, individualization cannot even be the primary function, but a name is used to express images relating to the place (...) The same phenomenon apllies, for example, to unofficial personal names. The prerequisite for intentionally ridiculing someone by using an abusive name is above all that this name contains certain meanings that can be interpreted in a certain way.
} 
Onomástica Desde América Latina, n.4, v.2, julho - dezembro, 2021, p. 70-94. ISSN 2675-2719 https://doi.org/10.48075/odal.v0i0.27562

da semântica lexical. (SPEBER \& WILSON, 2001 [1995]). Considerando a data de publicação da primeira edição de obra supramencionada e o modo como as disciplinas da Linguística estavam organizadas no mundo anglófono, entende-se que os autores não comungavam de todas as abordagens que então se faziam à Semântica Lexical ou delas discordavam parcialmente ou, então que, adotavam alguns princípios de uma abordagem e outros de outra.

Considerando a descrição de Cruse (2000: 96-102) sobre as abordagens no interior do que se abrangia sob a rubrica da "lexical semantics", a afirmação de que o viés adotado é eclético se justifica em virtude de Sperber e Wilson defenderem que o significado de uma palavra corresponde a um ou mais conceitos, o que leva a supor que eles compartilham de uma abordagem de nível unitário e do tipo conceitual. Em outras palavras, eles partem do pressuposto de que, para cada item lexical, há um ou mais conceitos associados e não havendo uma separação estanque entre nível semântico de um lado e nível extralinguístico de outro. De fato, essa abordagem não parte de uma dicotomia entre um nível semântico e um nível enciclopédico e ao invés de haver uma descontinuidade entre gramática e significado lexical/enciclopédico há um contínuo, ponto de vista defendido pela maioria dos linguistas cognitivos (CRUSE, 2000: 97).

Confirma a contribuição da Linguística Cognitiva à Teoria da Relevância a convergência encontrada no fato de as teorias definirem o significado no nível lexical de modo semelhante pois ambas adotam uma abordagem conceitual. "As abordagens conceituais (pelo menos como o termo é usado aqui) são abordagens de nível único e identificam o significado de uma palavra ( ou de pelo menos a maioria delas) com o 
Onomástica Desde América Latina, n.4, v.2, julho - dezembro, 2021, p. 70-94. ISSN 2675-2719 https://doi.org/10.48075/odal.v0i0.27562

conceito a que ela dá acesso no sistema cognitivo 3 "(CRUSE, 2000:100-101) (trad.minha) e, de acordo com a perspectiva da Teoria da Relevância, se supõe “ (...) que o <<significado >> de uma palavra é fornecido pelo conceito que lhe está associado (ou pelos conceitos lhe estão associados no caso de se tratar de uma palavra ambígua"(SPERBER \& WILSON, 2001 [1995]:149).

Menções aos nomes próprios são feitas pelos criadores da Teoria da Relevância quando afirmam:

\begin{abstract}
A maior parte das teorias da semântica lexical supõe que todas as palavras, com a possível excepção dos nomes próprios, têm significados do mesmo formato. Elas assim diferem de acordo com o modelo desse formato universal. Reconhecemos a possibilidade de as diferentes palavras poderem ter significados de formatos diferentes (SPERBER \& WILSON, 2001 [1995]:149)
\end{abstract}

Parágrafos adiante eles retomam a teoria clássica de que os nomes próprios são vazios de significado e informam como a TR lidaria com palavras: "Se assim for, se existirem palavras que tenham uma referência, mas que não tenham nenhumas condições lógicas ligadas a si (sic), de novo a nossa teoria pode facilmente tratar delas associando-as a conceitos que tenham uma entrada lógica vazia". (SPERBER \& WILSON, 2001 [1995] :150).

Colocada esta possibilidade, os autores consideram a teoria causal da referência e a teoria do protótipo e sobre elas afirmam que essas teorias não dão conta de descrever cabalmente os componentes semânticos e lógicos do significado, nem como esses componentes estão relacionados entre si, mas os pesquisadores não chegam a tomar um posicionamento claro sobre o assunto:

\footnotetext{
${ }^{3}$ Conceptual approaches (at least as the term is used here) are single-level approaches and identify the meaning of a word (or at least a major part of it) with the concept it gives access to in the cognitive system
} 
Onomástica Desde América Latina, n.4, v.2, julho - dezembro, 2021, p. 70-94. ISSN 2675-2719 https://doi.org/10.48075/odal.v0i0.27562

A nossa teoria permite entradas lógicas vazias, entradas lógicas que equivalem a uma definição apropriada do conceito e entradas lógicas que recaem em qualquer ponto entre estas duas extremidades: isto é, que fornecem alguma especificação lógica do conceito sem o definir totalmente. (SPERBER \& WILSON, 2001 [1995]:152).

Toda a explicação que segue, volta-se à análise de nomes comuns não havendo nenhuma outra consideração explícita aos nomes próprios, do que se conclui que, apesar de haver algumas menções aos nomes próprios, eles não são enfatizados na proposta inicial da TR, lacuna que o ensaio inicial proposto em 2014, por Seide, tentou sanar. Naquela ocasião, houve a retomada do seguinte diálogo criado e analisado por Sperber e Wilson:

Maria: Aquilo que eu gostaria de comer esta noite era um ossobuco. Pedro: Tive um dia esgotante. Estou cansado.

(SPERBER\& WILSON, 2001: 225)

Maria: Se estás cansado, farei o jantar (SPERBER \&WILSON, 2001: 225)

Seguindo-se os pressupostos da teoria, a intepretação da fala de Pedro por Maria é feita, por etapas não necessariamente consecutivas. Há uma etapa de decodificação linguística, seguida da ampliação do contexto cognitivo inicial pelo qual porções de informações são ativadas e, com base nelas, são feitas inferências e deduções que levam à interpretação do enunciado.

A reposta de Maria indica que ela concluiu que Pedro não tinha a mínima condição de preparar um ossobuco no jantar. Mas como ela chegou a esta conclusão? Como ela entendeu que o esgotamento o impossibilitaria de fazer o jantar? A interpretação de como ele estava se sentindo vai além do linguisticamente codificado pois dependem de informação adicional que se tornar acessível à Maria via ampliação do contexto cognitivo inicial. Este contexto expandido abrange o que Maria sabe de Pedro: que ele é um cirurgião-dentista, que tinha feito um implante coronário naquele dia e que, sendo o procedimento muito cansativo, nos dias em que ele faz o implante 
Onomástica Desde América Latina, n.4, v.2, julho - dezembro, 2021, p. 70-94. ISSN 2675-2719 https://doi.org/10.48075/odal.v0i0.27562

não consegue fazer mais nada. Com base nestas informações é que ela chega à conclusão sobre a impossibilidade de Pedro cozinhar o que a leva a decidir faze ela mesma a janta.

No caso desse diálogo, várias porções de informação foram ativadas por Maria. Entre as descritas pelos pesquisadores, as seguintes foram destacadas por Seide:

Porção 1. Informações enciclopédicas sobre o Pedro, incluindo a suposição: Pedro é cirurgião [...] Porção 6. Informações enciclopédicas sobre cirurgia [...] Porção 9. As informações enciclopédicas sobre um implante coronário, incluindo a suposição: Fazer um implante coronário é esgotante' (SPERBER \& WILSON, 2001, p.226, apud SEIDE, 2014:158.)

Com base nesta ampliação, a fala de Pedro é interpretada por Maria que lhe responde "Maria: Se estás cansado, farei o jantar" (SPERBER \& WILSON, 2001: 226). Sua resposta evidencia que ela avaliou que Pedro não tinha condições de preparar o jantar.

De acordo com o exemplo analítico ora retomado, a expansão do contexto inicial é uma etapa crucial da explicação do fazer interpretativo proposta pela TR. Essa etapa se baseia na ativação de determinadas informações que fazem parte daquilo que Sperber e Wilson chamam de conceito assim definido: "um título sobre o qual podem ser armazenados e recuperados vários tipos de informação" (SPERBER \& WILSON, 2001, :144). O conceito, por sua vez, é formado por 3 componentes: entrada lexical, entrada lógica e entrada enciclopédica (SPERBER \& WILSON, 2001:153).

$\mathrm{Na}$ primeira, ficam estocadas informações gramaticais e lexicais sobre as palavras, na segunda, as regras de dedução e de inferência e, na última, a terceira, as que relacionam à "extensão e/ou denotação do conceito, isto é, sobre os objetos, acontecimentos e/ou propriedades que os representam" (SPERBER \& WILSON, 2001:144). O conjunto formado pelas entradas forma um objeto psicológico abstrato (o conceito) que fica em um endereço conceitual na mente. Os autores esclarecem que 
Onomástica Desde América Latina, n.4, v.2, julho - dezembro, 2021, p. 70-94. ISSN 2675-2719 https://doi.org/10.48075/odal.v0i0.27562

[...] poderão existir conceitos que tenham entradas enciclopédicas e lógicas e que desempenhem um papel nos processos cognitivos, mas que não estejam lexicalizados e que, portanto, tenham uma entrada lexical vazia. Exemplificando: parece razoável supor-se que, correspondendo a conceito geral lexicalizado de "os militares" ou "as forças armadas", tenhamos um conceito especial de um soldado/marinheiro/aviador, a que falta uma entrada lexical (SPERBER \& WILSON, 2001:153).

Reavaliando a análise de Sperber e Wilson, percebe-se que eles propuseram a ativação de conceitos expressos por nomes comuns, como é o caso de cirurgia e cirurgião e de conceitos relativos a ações, como fazer um implante coronário. Há também a ativação do conceito relativo à Pedro que inclui a informação sobre cirurgião. Na ampliação da TR proposta por Seide (2014), defende-se a importância de se explicitar que o nome próprio Pedro é um conceito no qual vai se inclui tudo o que Maria sabe sobre ele, com inclusão de suas vivências e práticas discursivas tanto aquelas em que ele interage com ela quanto aquelas nas quais Pedro é o assunto da conversa.

Para exemplificar esta amplificação da proposta inicial de Sperber e Wilson Seide criou e analisou uma elocução que seria a parte inicial de um diálogo no qual Maria narra o acontecido à Joana, dizendo-lhe: "Maria: Eu queria que Pedro fizesse o jantar, mas ele me disse que estava cansado então, eu mesma o fiz".

A interpretação, por parte de Joana, requer que ela tenha, em sua mente, um conceito de Pedro que seja convergente ao de Joana no qual haja compartilhamento de algumas das descrições definidas atribuíveis a Pedro:

\footnotetext{
Para que Joana consiga interpretar o relato da amiga é preciso que ela ative informações enciclopédicas semelhantes àquelas que Maria ativou sobre Pedro: se Joana sabe que Pedro é um cirurgião e que seu trabalho o deixa exausto, ela pode deduzir que Pedro não faria o jantar. Tanto o processamento da elocução de Maria por Joana, quanto o processamento da elocução de Pedro por Maria são respaldados pelo conhecimento a respeito de Pedro, conhecimento socialmente partilhado (SEIDE, 2014:159).
}

Do ponto de vista adotado neste artigo, a ativação do conhecimento socialmente partilhado sobre Pedro se dá partir do nome próprio Pedro concebido como um 
Onomástica Desde América Latina, n.4, v.2, julho - dezembro, 2021, p. 70-94. ISSN 2675-2719 https://doi.org/10.48075/odal.v0i0.27562

endereço conceitual e não apenas como um código linguístico pelo qual Pedro seria mera e exclusivamente um substantivo próprio.

Ativando-se o endereço conceitual Pedro pelo seu uso em contexto, há, nas mentes das interlocutoras Joana e Maria, uma ativação que tudo o que elas sabem sobre o nome próprio Pedro e sobre o portador desse nome. Este pareamento entre conhecimento linguístico e conhecimento de mundo é outra evidência da necessidade de redefinição de nome próprio e encontra respaldo em achados neurolinguísticos, conforme se explica melhor na próxima seção deste artigo.

\section{Os achados neurolinguísticos e o conhecimento onomástico do falante ideal}

Nesta seção são retomadas as descobertas da Neurolinguística relatadas por Van Langendonck (2007) e reanalisadas por Seide (2014:153-155). Interessa aos propósitos deste artigo os achados decorrentes de um estudo de caso de um paciente italiano designado pela sigla PC citado por Van Langendonck. Este paciente foi acometido por um tipo de afasia que comprometeu totalmente o processo de recuperação de nomes próprio de sua memória ao mesmo tempo que manteve o acesso às informações relativas aos nomes comuns, o que explica o fato de o paciente conseguir recuperar nomes próprios sincronicamente provenientes de nomes comuns.

Como se sabe, existe nomes comuns que podem ser usados como nome próprio como é o caso, por exemplo, dos nomes femininos Rosa e Margarida, nos quais todos percebem que são provenientes de substantivos comuns que designam nomes de flores. Em casos equivalentes na língua italiana, PC mostrou ser capaz de recuperar o substantivo comum da memória quando o examinador lhe dava pistas sobre o significado do substantivo comum. Foi realizado um teste para o sobrenome Verdi, homônimo do nome da cor verde, na língua italiana. Perguntado sobre quem tinha sido 
Onomástica Desde América Latina, n.4, v.2, julho - dezembro, 2021, p. 70-94. ISSN 2675-2719 https://doi.org/10.48075/odal.v0i0.27562

o compositor das óperas Ainda e La Traviata, ele não conseguia se lembrar do nome próprio do compositor. Contudo, na sequência, as seguintes informações foram fornecidas: "O sobrenome do compositor lembra uma cor, a primeira letra de seu sobrenome começa com V" ${ }^{4}$. De posse dessas informações, ele conseguiu recuperar o nome comum "verti". Em outro teste, lhe foram apresentadas imagens de pessoas famosas, políticos e celebridades da Itália e de outros países e lhe foi perguntado quem eram e quais eram os seus nomes. Apesar de ter conseguido fazer as associações das características peculiares a cada pessoa com respostas como "Primeiro Ministro, ele foi o primeiro socialista a ocupar esta posição em nosso país" e "Poeta muito famoso, considerado o pai da nossa literatura" ele foi incapaz de lembrar os nomes próprios dessas pessoas. Ao longo do experimento, inclusive, ele sempre esquecia o nome do examinador e perguntava o nome dele, o que ocorreu dez vezes ao longo do experimento. Os únicos nomes próprios que ele não esqueceu foram o seu próprio nome e o nome de seu país, a Itália. (LANGENDONCK, 2007:109).

Este caso foi interpretado como evidenciadores da existência de "dois processos distintos: (1) correlação nomes próprios e seus portadores e (2) associação entre as descrições definidas que descrevem linguisticamente as características peculiares de portadores dos nomes próprio e o nome próprio, sendo que cada processo forma um módulo de informação". (SEIDE 2014:155). Enquanto no caso do paciente italiano, sua afasia dissociou os módulos, nas pessoas normais eles são interligados como se visualiza na figura a seguir.

\footnotetext{
${ }^{4}$ As falas em discurso direto foram traduzidas por mim da língua inglesa conforme descrição fornecida por Van Langendonkc( 2007: 109)
} 
Onomástica Desde América Latina, n.4, v.2, julho - dezembro, 2021, p. 70-94. ISSN 2675-2719 https://doi.org/10.48075/odal.v0i0.27562

Figura 1. Interligação dos módulos

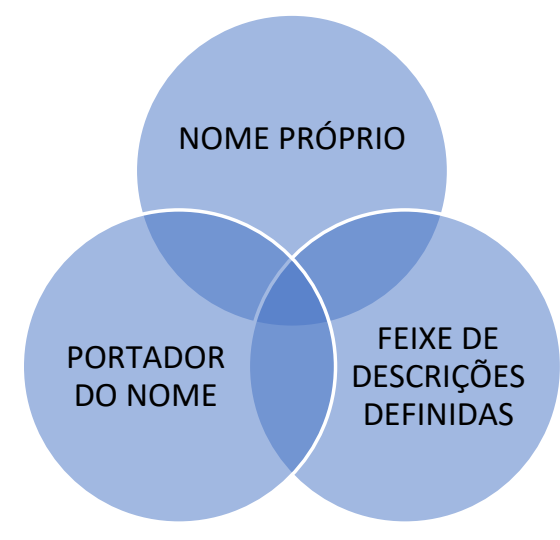

Fonte: Seide

Interpretando-se esses achados neuro-linguísticos à luz da Teoria da Relevância, eles podem ser analisados da seguinte maneira:

\begin{abstract}
"PC" tem, na mente, os endereços conceituais correspondentes aos nomes comuns e aos nomes próprios, porém, com relação aos últimos foram perdidas as entradas lexicais, mas não as enciclopédicas. A preservação das entradas enciclopédicas explica os acertos obtidos na correlação de características aos portadores dos nomes. As repetidas falhas de recuperação dos nomes próprios da memória, por sua vez, explicam-se pelo fato de não haver entradas lexicais pelas quais se possa ter acesso a esse tipo de nome. $\mathrm{O}$ sucesso de recuperação de nomes próprios homônimos, por fim, se deve ao fato de, neste caso, ser ativada a entrada lexical do nome comum (SEIDE, 2014:157).
\end{abstract}

De outro ponto de vista, os achados podem ser vistos como evidências indiretas daquilo que se constitui como sendo o conhecimento onomástico do falante ideal (SEIDE, 2021). A existência deste tipo de conhecimento parte do princípio de que a categoria dos nomes próprios faz parte daquilo que um falante nativo sabe sobre sua língua materna (podendo também ter conhecimentos de uma ou mais línguas estrangeiras e ter mais de uma língua materna), uma porção de conhecimento designada como competência onomástica ou conhecimento onomástico (COSERIU,1985; ORTEGA OJEDA, 1994, LÓPEZ FRANCO, 2014).

O conhecimento onomástico do falante ideal (doravante CO) é assim descrito por Seide: 
Onomástica Desde América Latina, n.4, v.2, julho - dezembro, 2021, p. 70-94. ISSN 2675-2719 https://doi.org/10.48075/odal.v0i0.27562

Faz parte do conhecimento onomástico do falante, o conhecimento sobre as características linguísticas dos nomes próprios em sua língua materna e sobre como eles são usados na comunidade linguística da qual ele faz parte. Ressalte-se que este conhecimento pode ou não incluir àqueles relacionados ao estudo do significado etimológico dos nomes próprios, mas, com certeza, inclui as crenças e atitudes do falante a respeito desses nomes (...). Enquanto as crenças dizem respeito a como cada um concebe o modo como os nomes devem ou podem ser e inclui critérios subjetivos responsáveis pela avaliação (positiva, neutra ou negativa) de nomes próprios, as atitudes indicam se os nomes próprios são vistos como sendo semanticamente opacos ou transparentes, isto é, se apresentam algum significado ou têm, meramente, uma função referencial (2021: 60).

A partir desta definição, foi proposta uma descrição deste conceito pensada para abranger o conhecimento relativo ao prenome, a qual foi adaptada para possibilitar que seja aplicada a todos os tipos de nome próprio. A tabela 1 apresenta a versão ampliada da proposta por Seide:

Tabela 1 . Conhecimento onomástico do falante - $\mathrm{CO}$ 1.significado denominativo procedural na linguagem cotidiana (como os nomes próprios são usados ) 2.relação entre nome e referente conhecidos ou mencionadas no cotidiano (que nomes as pessoas e os lugares têm, por exemplo )

3.repertório (conjunto e tipos de nomes próprios conhecidos; pode incluir nomes em outros idiomas) 4.pronúncia dos nomes conhecidos e regras supostas para pronúncia de nomes desconhecidos (como os nomes são pronunciados)

5.grafia segundo as regras ortográficas do idiomas (pode incluir conhecimento sobre a grafia de nomes de outros idiomas).

6.informação gramatical ( como gênero e número dos nomes próprios ${ }^{5}$ )

7.constituição (número de nomes de pode haver em um prenome ou em um topônimo por exemplo) 8.significado associativo (forma-se de acordo com as vivências do falante, com os referentes dos nomes) 9.significado emotivo (presente, por exemplo, nos hipocorísticos nos quais há uma conotação afetiva nos nomes)

10.fatores sociolinguísticos (presunção sobre a classe social e o gêneros dos nomes de pessoas, por exemplo)

11.imaginários etnosocioculturais (como presunção sobre qualidades atribuídas aos nomes como a de que nomes de pessoa em língua inglesa teê mais prestígio do que nomes na língua portuguesa)

12.processo de nomeação: quem nomeia e quando (pode incluir os aspectos legais da nomeação oficial)

13.motivação da nomeação (conhecimento sobre a história da escolha do nome, do porquê um determinado nome foi escolhido )

14.usos e valores de prenomes no mundo ficcional (literatura, cinema, mini-séries, telenovelas, games, etc.)

15.significado etimológico e/ou histórico

Fonte : Adaptado de Seide, 2021: 67

Considerando que o nome próprio é um endereço conceitual que leva às entradas

lógica, lexical, gramatical e enciclopédica, os componentes do conhecimento ou competência do falante, ora descritos, abrangem as duas primeiras: enquanto as

\footnotetext{
${ }^{5}$ A informação gramatical depende da língua em questão, no caso de línguas declinatórias, como a língua lituana, há também informação sobre os casos e suas declinações.
} 
Onomástica Desde América Latina, n.4, v.2, julho - dezembro, 2021, p. 70-94. ISSN 2675-2719 https://doi.org/10.48075/odal.v0i0.27562

competências 2 a 7 correspondem à entrada gramatical dos nomes próprios, a demais informações respondem pela entrada enciclopédica.

É preciso ressaltar, entre os componentes da entrada enciclopédica, o componente número 8 que está relacionado à interpretação dos diálogos analisados neste artigo e os itens 13, 14 e 15 que são aspectos eruditos do conhecimento onomásticos, sendo por isso muito variável de uma pessoa a pessoa. De fato, o conhecimento onomástico, longe de ser homogêneo, apresenta muitas gradações de acordo com o interesse dos falantes:

\begin{abstract}
No entanto, parece lógico supor que, sobretudo por causa da profissão ou da predileção que tenham, serão determinados indivíduos os que terão uma competência onomástica maior: taxistas, mensageiros, carteiros, repartidores, cobradores a domicílio, fãs ou comentaristas de determinados esportes, críticos musicais, etc. ${ }^{6}$ (ORTEGA OJEDA, 1994:303) (trad. minha)
\end{abstract}

Pela união das propostas de nome próprio como endereço conceitual e como parte do conhecimento linguístico do falante ideal, chega-se à redefinição do conceito de nome próprio destacada no quadro 02 a seguir.

Quadro 02. Redefinição do conceito de nome próprio

O nome próprio é um nome singular, um objeto abstrato armazenado num endereço conceitual na mente do falante composto por um componente lógico, um componente lexical e um componente enciclopédico. Enquanto o primeiro responde pelo processamento necessário das informações para se chegar à compreensão de elocuções nas quais os nomes próprios são utilizados, os dois últimos integram o conhecimento linguístico e de mundo relativos ao nome próprio e correspondem ao conhecimento onomástico do falante ideal e pode abranger desde o conhecimento como em determinada língua e cultura os nomes são usados e suas características gramaticais até o conhecimento erudito sobre a etimologia e a origem dos nomes.

Fonte: Seide

\footnotetext{
${ }^{6}$ Sin embargo, parece lógico suponer que, sobre todo por razón del oficio o de la afición que practican, serán determinados individuos los que posean una mayor competencia onomástica: taxistas, mensajeros, carteros, repartidores, cobradores a domicilio, aficionados o comentaristas de ciertos deportes, críticos musicales, etc.
} 
Onomástica Desde América Latina, n.4, v.2, julho - dezembro, 2021, p. 70-94. ISSN 2675-2719 https://doi.org/10.48075/odal.v0i0.27562

O nome próprio é um objeto abstrato armazenado num endereço conceitual na mente do falante, composto por um componente lógico, um componente lexical e um componente enciclopédico. Enquanto o primeiro responde pelo processamento necessário das informações para se chegar à compreensão de elocuções nas quais os nomes próprios são utilizados, os dois últimos integram o conhecimento linguístico e de mundo relativos ao nome próprio e correspondem ao conhecimento onomástico do falante ideal e pode abranger desde o conhecimento como em determinada língua e cultura os nomes são usados e suas características gramaticais até o conhecimento erudito sobre a etimologia e a origem dos nomes,

\section{Algumas implicações da redefinição de nome próprio para os estudos onomásticos}

O proposto no quadro 2 , ao que se sabe até o momento de produção deste artigo, é uma redefinição inédita na literatura dos estudos onomásticos que transcende o encontrado nas gramáticas brasileiras. Trata-se de uma nova definição na qual convergem o conhecimento linguístico e de mundo do falante ideal e se levam em consideração as entradas lógica, lexical e enciclopédica que formam o objeto psicológico abstrato inscrito na mente, como um endereço conceitual.

Há vantagens na utilização desta nova definição de nome próprio. Uma delas é que seu uso pode proporcionar uma compreensão ao mesmo tempo abrangente e precisa sobre as pesquisas que têm sido feitas na área da Onomástica ${ }^{7}$ quando se considera que o conhecimento produzido pelos pesquisadores faz parte do próprio conhecimento onomástico dos pesquisadores, entre outras palavras, os objetos de estudo investigados são vistos como parte do conhecimento onomástico $(\mathrm{CO})$ dos pesquisadores.

\footnotetext{
7 Veja-se a este respeito a revisão de literatura de estudos recentes na área em âmbito nacional e internacional feita por Amaral e Seide (2020).
} 
Onomástica Desde América Latina, n.4, v.2, julho - dezembro, 2021, p. 70-94. ISSN 2675-2719 https://doi.org/10.48075/odal.v0i0.27562

O quadro 02, a seguir, reúne e caracteriza o objeto de estudo de algumas pesquisas publicadas no terceiro número da revista Onomástica desde América Latina, no primeiro semestre de 2021, para mostrar como esta definição enriquecida, do nome próprio, pode ser usada para a organização epistemológica da área.

Quadro 03 Caracterização de pesquisas onomásticas recentes

\begin{tabular}{|l|l|l|}
\hline Artigo & Entrada(s) & Componente do CO \\
\hline Ragauskaitė (2021) & lexical & 6,7 e 15 \\
\hline Vescovi (2021) & lexical e enciclopédica & 1,3 e 10 \\
\hline Reyes Contreras (2021) & lexical e enciclopédica & $1,3,6$ e 8 \\
\hline Fray (2021) & lexical e enciclopédica & $1,3,12$ e 13 \\
\hline Cruz; Amaral (2021) & lexical e enclopédica & $1,2,3$ e 7 \\
\hline $\begin{array}{l}\text { Taibi-Maghraoui } \\
\text { (2021) }\end{array}$ & lexical & 1,3 e 15 \\
\hline Ruppenthal (2021) & lexical e enciclopédica & $1,2,3$, e 13 \\
\hline Junges (2021) & lexical e enciclopédica & $1,2,3$ e 13 \\
\hline
\end{tabular}

A leitura do quadro 3 além de permitir visualizar as diferenças e semelhanças entre as pesquisas, possibilita saber o tipo de pesquisa desenvolvido. Os artigos de Ragauskaitė e de Taibi-Maghraoui, por exemplo, são os únicos do elenco que não lidam com as informações que fazem parte da entrada enciclopédica e analisam o componente 15 do $\mathrm{CO}$ que se refere ao significado histórico e /ou etimológico dos nomes próprios. De fato, ambos os trabalhos de inserem na mesma subárea ,a da Onomástica Histórica e suas análises não requerem contribuição com outras disciplinas ou áreas do conhecimento: no primeiro artigo é analisado do ponto de vista morfológico e etimológico um conjunto de nomes de pessoas registrado na paróquia mais antiga da Lituânia no período de 1599 a 1621; no segundo, é comparada a frequência de nomes com significado histórico e etimológico religioso em duas amostras de nomes de pessoas registradas em cartório em uma cidade da Argélia recobrindo uma delas o período de 1875 a 1885 e, a outra, o período de 1962 a 2010.

Pela leitura do quadro é também possível identificar quando duas pesquisas diferentes são epistemologicamente equivalentes. Este é o caso das pesquisas de 
Onomástica Desde América Latina, n.4, v.2, julho - dezembro, 2021, p. 70-94. ISSN 2675-2719 https://doi.org/10.48075/odal.v0i0.27562

Ruppenthal (2021) e Junges (2021) que analisam nomes de escolas em duas cidades do Oeste do Paraná: a primeira em Marechal Cândido Rondon e a segunda em Missal. Ambas as análises repertoriam os nomes com base em pesquisa documental nos Projetos Políticos Pedagógicos das escolas e relacionam a história das cidades e das escolas à história dos nomes escolhidos.

Outra consideração importante sobre o que o quadro 02 evidencia diz respeito ao tipo de pesquisa empreendido: se disciplinar ou interdisciplinar, tendo em vista que todas as pesquisas que lidam com a entrada enciclopédica transcendem os limites dos estudos linguísticos. Vescovi (2021) e Frai (2021) relacionam mudanças no repertório de prenomes de pessoas nascidas nas localidades por elas estudadas, respectivamente, Palotina e Marechal Cândido Rondon, à história dessas cidades do Oeste do Paraná. Cruz e Amaral (2021), por sua vez, analisam prenomes presentes em convocações de jogos profissionais de futebol, tendo por base as regras dos torneios e as características desse esporte e Reyes Contreras (2021) analisa uma amostra de nomes de bandas de Heavy Metal para o que necessitou considerar não só a história e evolução deste estilo de música, mas também a relação entre os nomes de banda e os nomes de marcas.

No caso das pesquisas mencionadas, considerou-se os pesquisadores como aqueles cujo conhecimento onomástico demonstrado pelas investigações empreendida foi analisado. Quando se consideram as pessoas em geral como aqueles cuja competência é o objeto de estudo surgem muitas perspectivas de pesquisas a serem realizadas. No artigo em que o $\mathrm{CO}$ foi primeiramente descrito, um dos objetivos da pesquisa de Seide (2021) foi analisar, segundo resultados de uma amostra de questionário preenchidos por alunos de Licenciatura de uma universidade pública da região oeste do Paraná, o conhecimento sobre nomes religiosos por parte dos portadores 
Onomástica Desde América Latina, n.4, v.2, julho - dezembro, 2021, p. 70-94. ISSN 2675-2719 https://doi.org/10.48075/odal.v0i0.27562

desses nomes. Muitas outras pesquisas podem ser delineadas e desenvolvidas nessa direção.

\section{Considerações Finais}

Este artigo teve por objetivo propor uma definição interdisciplinar de nome próprio que agregasse conhecimento de mundo e conhecimento linguístico, ambos necessários tanto aos usos dos nomes próprios em sociedade quanto ao seu estudo científico por parte dos onomasticistas. Inicialmente foram recuperadas de gramáticas normativas e descritivas definições de nomes próprios as quais convergiam em apontar sua função de fazer referência a um ser único no mundo.

Neste ponto, foi retomada a questão filosófica a respeito do geral e do particular, tendo em vista que os nomes comuns correspondem aos primeiros e os nomes próprios aos segundos e a discussão sobre se seria possível haver uma linguagem na qual não houvesse nomes particulares. A resposta a esta questão trouxe à tona a possibilidade de substituir nomes próprios por frases e descrições definidas que descrevessem o referente ou portador do nome. Tendo em vista que o conjunto das frases e descrições que se pode atribuir ao referente remetem a um conhecimento enciclopédico surge a hipótese de pareamento entre o conhecimento linguístico e o conhecimento enciclopédico sobre os nomes próprios e os seus portadores.

Mostrou-se então que a hipótese levantada encontra respaldo na Teoria da Relevância a qual propõe que um item lexical está armazenado na memória num endereço conceitual no qual se unem um componente lógico, um componente enciclopédico e um componente lexical, proposta que encontra respaldo em achados neuro-linguísticos em experimentos realizados em pacientes afásicos que apesar de conhecerem os referentes dos nomes próprios e as características que as definem e caracterizam, mas não conseguem associá-lo aos nomes próprios que os nomeiam, 
Onomástica Desde América Latina, n.4, v.2, julho - dezembro, 2021, p. 70-94. ISSN 2675-2719 https://doi.org/10.48075/odal.v0i0.27562

resultados de pesquisam evidenciadores de que, em pessoas normais o conhecimento sobre o nome próprio e sobre o seu portando são acessíveis e entre si relacionados.

A aproximação de conhecimento de mundo e conhecimento linguístico também é defendida pela Linguística Cognitiva na qual se pauta a Teoria da Relevância e a Onomástica Cognitiva a qual leva em conta o conhecimento enciclopédico ao constatar que nem sempre o nome próprio é usado meramente por sua função de fazer uma referência unívoca o que se percebe, por exemplo, na criação e no uso de apelidos e de nomes de lugares não oficiais nos quais certas características do referente são expressas e enfatizadas.

Pela integração destas duas ordens de conhecimento na descrição do conhecimento onomástico do falante ideal surge a proposta de redefinição apresentada neste artigo. Espera-se que este constructo teórico seja útil a pesquisadores que desejem realizar pesquisas interdisciplinares em Onomástica partindo de uma definição também interdisciplinar de nome próprio como endereço conceitual estão armazenadas (em graus diferentes conforme a subjetividade dos indivíduos) todas as informações que se podem atribuir a estes tipo de nome e aos seus portadores, com inclusão dos aspectos mais eruditos desde conhecimento como a história da motivação do nome próprio, de suas causas históricas e do seu significado etimológico.

Cumpre ressaltar, por fim, que a descrição mais pormenorizada do conhecimento onomástico do falante ideal que se faz neste artigo pode ser usada como ferramenta epistemológica à medida possibilita visualizar que componentes são considerados e quais são ignorados numa pesquisa onomástica específica permitindo que se possa analisar se uma investigação é exclusivamente linguística ou se é interdisciplinar. 
Onomástica Desde América Latina, n.4, v.2, julho - dezembro, 2021, p. 70-94. ISSN 2675-2719 https://doi.org/10.48075/odal.v0i0.27562

\section{Referências}

Amaral, E.T,R.\&, Seide, M.S.S. (2020) Nomes próprios de pessoas: introdução à antropononímia brasileira. São Paulo: Blucher: 2020. https://doi.org/10.5151/9786555500011

Bréal, M. (1992 [1904]) Ensaio de Semântica.Trad.de F.Aída et.al.São Paulo:Pontes/Educ.

Carvalhinhos, P., \& Santos, C. A. N. (2021). Os nomes próprios entre o logos e a práxis. Domínios De Lingu @gem, 15(2), 263-298. https://doi.org/10.14393/DL46v15n2a2021-1

Cegalla, D. P. (1964) Novíssima Gramática da Língua Portuguesa. São Paulo: Companhia Editora Nacional.

Coseriu, E. Linguistic Competence (1985). What Is It Really? The Modern Language Review, [S.1.], v. 80. n. 4, 25-35, 1985.

Cunha, C. F. Teorias Descritivistas do Nome Próprio (2010). Dissertatio, v.30, 185 195.

Cunha; C.; Cintra, L. (1985). Nova Gramática do Português Contemporâneo $2^{\text {a }}$.ed.Rio de Janeiro 2a.ed.Ed.Nova Fronteira, 1985.

Cruse, D. A. (2000). Meaning in Language. An Introduction to Semantics and Pragmatics. Oxford: Oxford University Press, 2000.

Cruz, V. S.\& Amaral, E. T. (2021) Variação e mudança em nomes de jogadores da Seleção Brasileira. Onomástica Desde América Latina, n.3, v.2, janeiro - junho, 2021, 101118. https://doi.org/10.48075/odal.v0i0.25720

Faraco, C. E.\& Moura, F. M. de. (1990) Gramática. Fonética e Fonologia. Morfologia. Sintaxe. Estilística.4 $4^{\mathrm{a}}$.ed., São Paulo: Ática.

Frai, H. (2021).Tendências religiosas na antroponímia rondonense. Onomástica Desde $\begin{array}{llllllll}\text { América Latina, } & \text { n.3, } & \text { v.2, janeiro } & - & \text { junho, } & 82 & - & 100 .\end{array}$ https://doi.org/10.48075/odal.v0i0.25725

Junges, B. (2021). Toponímia oficial e toponímia espontânea nos nomes de escola de Missal- PR Onomástica Desde América Latina, n.3, v.2, janeiro - junho, 132 - 153.

https://doi.org/10.48075/odal.v0i0.25742

López-franco, Y. G. (2014) El semanticismo de los nombres proprios. Revista Trama, Marechal Cândido Rondon, PR, v.10, n. 20, 69-81.

Mill, S. (1984) Sistema de lógica dedutiva e indutiva e outros textos. In: BENTHAM, Jeremy. Uma introdução aos princípios da moral e da legislação. $3^{a}$.ed. São Paulo: Abril Cultural, (Coleção Os Pensadores, v.34). 
Neves, M. H. de M. (2000). Gramática de usos do português. São Paulo: UNESP.

Ortega-Ojeda,G.(1994) La competência onomástica dialetal, a propósito del caso canário. Revista de Filologia de la Universidad de La Laguna, San Cristobal de La Laguna, Espanha,n.13, 291-307.

Pereira Júnior, F. A. (1924). Grammatica Pratica. Curitiba:Empreza Graphica Paranaense.

Ragauskaite, A. Tendencies of formation of anthroponyms of rural residents in the oldest Lithuanian parish register of Joniškis dated 1599-1621.(2021). Onomástica Desde América Latina, n.3, v.2, janeiro - junho, $2 \quad-\quad 29$. https://doi.org/10.48075/odal.v0i0.25781

Reunião de professores. Gramática. (1937). Lexicologia, Análise, Composição. Rio de Janeiro: Livraria Francisco Alves.

Reyes Contreras, M. (2021)Acercamiento onomástico al nombre de las bandas de Heavy Metal. Onomástica Desde América Latina, n.3, v.2, janeiro - junho, 59-81. https://doi.org/10.48075/odal.v0i0.26062

Ruppenthal, D. S. (2021). Nomeação de escolas como homenagem à história local do município paranaense de Marechal Cândido Rondon. Onomástica Desde América Latina, n.3, v.2, janeiro - junho:153-176. https://doi.org/10.48075/odal.v0i0.25692.

Seide, M. S. Prenomes cristãos: constituição, etimologia, motivação para a escolha antroponímica e conhecimento onomástico. REVISTA DE ESTUDOS DA LINGUAGEM, [S.1.], v. 29, n. 1, p. 49-76, jan. 2021. ISSN 2237-2083. Disp.em: <http://www.periodicos.letras.ufmg.br/index.php/relin/article/view/16765>. Acesso em accessed: 06 junho 2021. doi:http://dx.doi.org/10.17851/2237-2083.29.1.49-76

Seide, M, S. Caracterização morfológica dos prenomes mais populares no Brasil nas décadas de 1930 a 2000: um estudo exploratório. Filologia e Linguística Portuguesa (no prelo)

Seide, M. S.\& Saparas, M. (2020). Trends in Onomastic Research in Brazil. Linguistik Online, 101(1), 139-155. https://doi.org/10.13092/lo.101.6681

Seide, M. S.\& Schultz, B. S. (2014). Linguagem, cognição e identidade: o estatuto dos nomes próprios. In: Ciências do Léxico. Lexicologia, Lexicografia. Terminologia. Vol. VII,Campo Grande: Editora UFMS, 2014:.149 - 166.

Sjöblom, P. A Cognitive Approach to the Semantics of Proper Names. (2006). Onoma v.41, 63-82, 2006 DOI 10.2143/ONO.41.0.2119611. Disp.em PEETERS ONLINE JOURNALS (peeters-leuven.be) Acesso em 08 março 2021. 
Onomástica Desde América Latina, n.4, v.2, julho - dezembro, 2021, p. 70-94. ISSN 2675-2719 https://doi.org/10.48075/odal.v0i0.27562

Sperber, D. \& Wilson, D. (2001). Relevância: comunicação e cognição. Lisboa: Fundação Calouste Gulbenkian. ALVES, H.S. (trad).

Taibi-Maghraoui, Y.(2021) L'anthroponymie religieuse en Algérie. Onomástica Desde América Latina, n.3, v.2, janeiro - junho:119-131.

https://doi.org/10.48075/odal.v0i0.25486

Van Langendock, W. (2007). Theory and typology of proper names. Berlin/New York: Mouton de Gruyter, 2007.

Vescovi, J. P. (2021). Eventos históricos e os impactos antroponímicos: a influência da Era da hortelã na antroponímia de Palotina - PR. Onomástica Desde América Latina, n.3, v.2, janeiro - junho:30-58. https://doi.org/10.48075/odal.v0i0.25970

Tunhas, P. (2001) Particular e universal: aspectos classificatórios, antropológicos, ontológicos e lógico-gramaticais. (2001). Discursos [Em linha]: língua, cultura e sociedade. ciclo de colóquios: uma tensão entre o global e o local. Lisboa: Universidade Aberta, 332-348. 